\title{
Mechanical performance and crack pattern analysis of aged Carbon Fabric Cementitious Matrix (CFRCM) composites
}

\author{
Cesare Signorinia $^{\mathrm{a}, *}$, Andrea Nobili ${ }^{\mathrm{b}}$, Federico O. Falope ${ }^{\mathrm{b}}$ \\ ${ }^{a}$ Dipartimento di Scienze e Metodi dell'Ingegneria (DISMI), University of Modena and \\ Reggio Emilia, Via Giovanni Amendola, 2, 42122 Reggio Emilia \\ ${ }^{b}$ Dipartimento di Ingegneria "Enzo Ferrari" (DIEF), University of Modena and Reggio \\ Emilia, Via Pietro Vivarelli, 10, 41125 Modena
}

\begin{abstract}
We discuss the effect of environmental exposure on mechanical performance of impregnated Carbon Fabric Reinforced Cementitious Matrix (CFRCM) composite. Following the recently published ICC-ES AC434 guidelines, mechanical performance of prismatic composite specimens is determined on the basis of tensile uni-axial tests. Exposure to saline and alkaline aqueous solutions is considered at 28- as well as 60-day curing time. Special emphasis is placed on crack pattern evaluation as a mean to gain better insight into matrix/fabric bond quality. To this aim, the evolution of the average crack spacing and of the average crack width is determined as a function of strain for all test environments and curing times. It is found that curing time plays a significant role in mitigating the detrimental effect of aggressive environments. Furthermore, the average crack spacing provides a very reliable measure of matrix/fabric bond degradation at all test stages.
\end{abstract}

Keywords: Durability; Textile reinforced mortar; Carbon fabric cementitious composite

\section{Introduction}

Continuous fibre composite materials have been actively investigated in the last three decades as effective materials for seismic retrofitting and strengthening. These lightweight and versatile composites can be grouped according to the organic/inorganic nature of the matrix, respectively FRP (Fibre Reinforced Polymers) and FRCM (Fabric Reinforced Cementitious Matrix) or TRC/TRM (Textile Reinforcement Concrete/Mortar). The reinforcement most commonly employed in FRP and FRCM consists of woven fabric (uni- or multi-axial)

\footnotetext{
${ }^{*}$ Corresponding author

Email address: cesare.signorini@unimore.it (Cesare Signorini)
} 
wherein fibres are usually chosen according to their strength and deformability. Fibres can be divided into conventional (steel and glass), high-modulus (typically aramidic, polyphenylenebenzobisoxazole (PBO) or carbon), low-modulus (polypropylene) or natural (straw, hemp, cellulose, flax). Low-modulus and natural fibres are more often employed in Fibre Reinforced Concrete (FRC) as discrete randomly-distributed reinforcing elements [1]. FRP have been widely investigated and adopted in engineering structures also in consideration of the wide availability of design criteria in many national codes (for instance [2]). However, FRP suffer from some severe drawbacks which hinder their general applicability and prompt demand for new technologies [3]. FRCM composite materials may be preferable owing to their composition, which appears compatible with the traditional inorganic (brick/mortar, cement) substrate, to their porosity, that warrants "breathability", to their resistance to high temperatures. Nevertheless, the adoption of FRCM composite is hindered by the lack of regulations. Recently, the International Code Council Evaluation Services (ICCES) [4] and the International union of laboratories and experts in construction materials, systems and structures (RILEM) [5] provided a backbone of regulations to implement FRCM composite materials. Besides, FRCM suffers from the lack of fabric-to-matrix adhesion, which leads to inconsistent performance and telescopic failure [6].

Material durability is a critical issue whose deep understanding is required before a material may undergo large scale application. Arboleda et al. [7, 8] investigated durability of carbon and PBO FRCM systems. In [9], the mechanical response of alkali-resistant glass (ARG) FRCM coupons after exposure to saline and alkaline environment is considered. A similar analysis is presented in [10] for several reinforcement fabrics in the alkaline environment. In [11, 12, 13] glass fabric durability in the alkaline environment is assessed through pull-out, tensile and bending tests. [14] considers the crack pattern evolution in uni-axial traction of low modulus woven polyethylene fabric and bonded AR-glass mesh TRC composites. In this paper, we investigate the effects of curing time and aggressive environment exposure on the mechanical performance of C-FRCM. According to the ICC guidelines, mechanical performance is assessed in uni-axial traction of prismatic coupons. Particular emphasis is placed on crack pattern evolution as a means to infer interphase bond quality.

\section{Materials and methods}

\subsection{Reinforcing fabric}

A commercially available square-grid bi-axial carbon fabric is adopted as the reinforcing phase (Figure 1). This fabric is produced by weaving and thermowelding high-tenacity multi-filament carbon yarns. The mechanical properties of the fabric are gathered in Table 1.

\subsection{Impregnating agent}

Fabrics are impregnated by immersion in a bi-component hybrid mineral/polymeric adhesion promoter (hereafter "impregnating agent"). The mineral component 


\begin{tabular}{|l|c|c|}
\hline Characteristic & Unit & Value \\
\hline Yarn count & $\mathrm{tex}$ & 800 \\
Specific weight per unit fabric area & $\mathrm{g} / \mathrm{m}^{2}$ & 200 \\
Fabric specific weight & $\mathrm{g} / \mathrm{cm}^{3}$ & 1.78 \\
Grid spacing (square grid side) & $\mathrm{mm}$ & 8 \\
Carbon fabric cross-sectional area (per unit width), $A_{f}$ & $\mathrm{~mm}^{2} / \mathrm{cm}$ & 0.56 \\
Ultimate strength along the principal direction (epoxy impregnated) & $\mathrm{N} / \mathrm{cm}$ & 1800 \\
Elastic modulus & $\mathrm{GPa}$ & 240 \\
\hline
\end{tabular}

Table 1: Carbon fabric mechanical properties $(1$ tex $=1 \mathrm{~g} / \mathrm{km})$

\begin{tabular}{|l|c|c|}
\hline Characteristic & Unit & Value \\
\hline Adhesion to concrete & $\mathrm{MPa}$ & $\geq 3$ \\
Flexural strength & $\mathrm{MPa}$ & $\geq 5$ \\
Ultimate strain & mstrain & $\geq 12$ \\
Flexural modulus & $\mathrm{MPa}$ & 50 \\
\hline
\end{tabular}

Table 2: Impregnating agent mechanical properties

acts as a filler and imparts superior resistance to the aggressive environments. The impregnated fabric is embedded in the cementitious matrix prior to setting of the polymeric phase (wet phase). The main mechanical and physical properties of the impregnating agent are reported in Table 2.

\subsection{Inorganic matrix}

A pre-mixed natural lime-based hydraulic mortar (NHL) is adopted as inorganic matrix and its main mechanical properties are presented in Table 3. This low-modulus mortar is especially designed to strengthen historical or aged masonry and it consistently develops high-quality bond with the impregnating agent.

\subsection{Specimen manufacturing}

Specimen manufacturing and testing are performed according to Annex A of [4]. Specimen preparation occurs on an individual basis in a specially designed

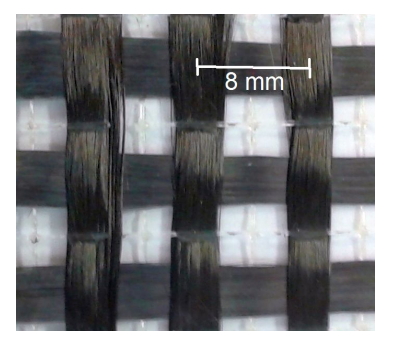

Figure 1: The multi-filament bi-axial carbon reinforcing fabric 


\begin{tabular}{|l|c|c|}
\hline Characteristic & $\mathrm{Unit}$ & Value \\
\hline Density of the mixture & $\mathrm{kg} / \mathrm{m}^{3}$ & 1700 \\
Mean compression strength after 28 days (UNI EN 12190) & $\mathrm{MPa}$ & $\geq 6.5$ \\
Mean flexural strength after 28 days (UNI EN 196/1) & $\mathrm{MPa}$ & $\geq 3$ \\
Support adhesion strength after 28 days & $\mathrm{MPa}$ & 1 \\
Water content & - & $23 \%$ \\
Aggregate maximum size & $\mathrm{mm}$ & 0.7 \\
Longitudinal elastic modulus & $\mathrm{GPa}$ & 11 \\
Water vapor permeability $\mu$ & - & 12 \\
\hline
\end{tabular}

Table 3: Mortar properties provided by the producer (Brigliadori Fornace Calce).

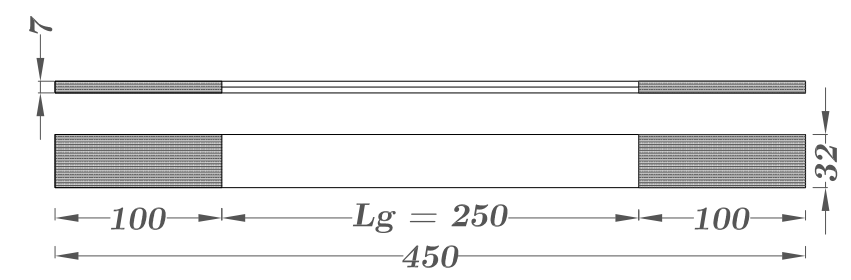

Figure 2: Coupon geometry (dimensions in $\mathrm{mm}$ )

modular polyethylene formwork, see $[9,3]$ for more details. The specimen geometry is illustrated in Figure 2 and, in conformity with the ICC guidelines [4], specimen width is an integer multiple of the mesh size, namely $w_{f}=320 \mathrm{~mm}$. According to $[2, \S 2.2 .3 .1]$, the laminate cross-sectional area is designed according to the following expression:

$$
A_{f}=\frac{T_{x} N_{f}}{10^{4} \rho_{f}} w_{s}=1.79 \mathrm{~mm}^{2}
$$

In Eq.(1), $T_{x}=800$ tex is the yarn count in the principal direction, $N_{f}=$ $1.25 \mathrm{~cm}^{-1}$ is the number of yarns per unit length and $\rho_{f}=1.78 \mathrm{~g} / \mathrm{cm}^{3}$ is the density of the carbon fibre. In the following, strength values are conventionally referred to this cross-sectional area.

As prescribed in $[15,16]$, moist-curing is carried out in a polypropylene bag for 7 days to prevent differential shrinkage between the top surface, exposed to air, and the bottom surface, in contact with the formwork. 28- and 60-day curing is considered. $100 \mathrm{~mm}$-long carbon fabric tabs are epoxy glued to the specimens ends to accommodate for the testing machine grips. Cured specimens are shown in Figure 3. The specimen gauge length (net of end tabs), $L_{g}$, is equal to $250 \mathrm{~mm}$. For statistical significance, a minimum of 5 specimens is considered in every test group.

\subsection{Aggressive environments}

The following aggressive solutions are considered, according to the prescriptions in [4]: 


\begin{tabular}{|l|c|c|c|c|c|}
\hline Test groups & $\begin{array}{c}\text { Curing } \\
\text { [days] }\end{array}$ & $\begin{array}{c}\text { Exposure } \\
\text { time }[\mathrm{hrs}]\end{array}$ & \multicolumn{2}{|c|}{ Temperature } & Ref. \\
& ${ }^{\circ} \mathrm{C}$ & $\mathrm{F}$ & \\
\hline Control (CC28/CC60) & $28 / 60$ & - & \multicolumn{2}{|c|}{ room } & - \\
Saline (SW28/SW60) & $28 / 60$ & 1000 & $23 \pm 1$ & $73 \pm 2$ & {$[4$, Table 2] } \\
Alkaline (AK28/AK60) & $28 / 60$ & 1000 & $23 \pm 1$ & $73 \pm 3$ & [4, Table 2] \\
\hline
\end{tabular}

Table 4: Tested environments; room temperature is $21 \pm 2^{\circ} \mathrm{C}(70 \pm 3.6 \mathrm{~F})$

- a $3.5 \%$-weight saline solution that represents ocean water average salinity. It is prepared dissolving pure sodium chloride into distilled water.

- an alkaline solution with $\mathrm{pH}=10$ (prescribed $\mathrm{pH} \geq 9$ ). It is prepared diluting in distilled water concentrated sodium hydroxide ( $\mathrm{NaOH}$, Sigma Aldrich Inc.) until $\mathrm{pH}$ reaches the target value.

Specimens age in a Memmert HP110 climatic chamber at constant temperature $T=37.7^{\circ} \mathrm{C}$ for 1000 hours [4]. The temperature in the chamber is double checked by an independent recorder.

\subsection{Curing time}

In order to correlate the maturation grade of the hydraulic matrix [15] with the loss of mechanical performance due to aging, 28 and 60-day curing is considered. Specimens groups and aging details are summarized in Table 4.

\subsection{Testing procedure}

Specimen performance is evaluated in uni-axial tensile tests through a Instron 5567 Universal Testing Machine (UTM), equipped with a $30 \mathrm{kN}$ load cell and wedge grips. Hinges warrant a uni-axial tensile stress state. Tests are carried out under displacement control with nominal rate $0.5 \mathrm{~mm} / \mathrm{min}$ (this translates in terms of nominal axial strain as $\dot{\varepsilon}=\dot{\delta} / L_{g}=2 \mathrm{mstrain} / \mathrm{min}$ ).

\subsection{Digital Image Correlation}

As already pointed out in [17], strength curves and crack evolution should be determined from actual specimen strain as opposed to imposed nominal strain. Indeed, the former is affected by the contribution of wedge grip elongation
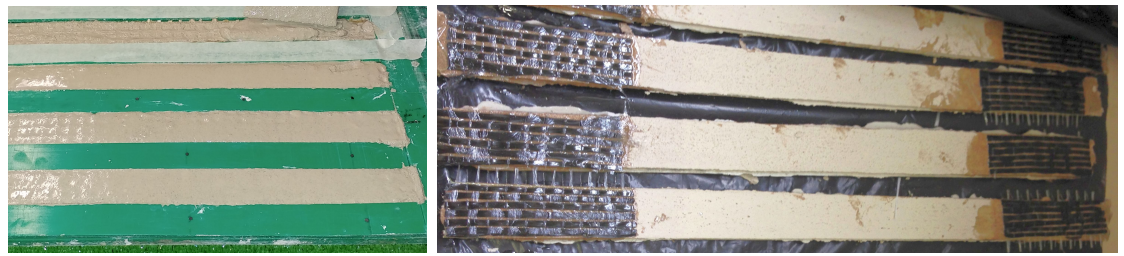

Figure 3: Two stages in specimen manufacturing: specimens cure in the modular formwork (left) and, after stripping, they are provided with end tabs (right). 


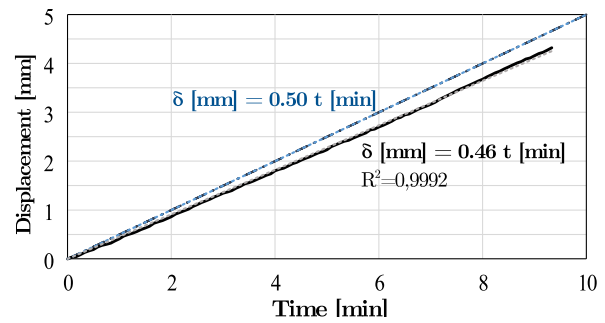

Figure 4: Nominal ramp (dotted line) vs. DIC acquired displacement data (solid line) and linear curve fitting expression

which is load dependent. To this aim, a Q400 Dantec Dynamics Digital Image Correlation (DIC) stereoscopic system is employed. Fig.4 compares the nominal ramp with the measured displacement as a function of time and it shows that a linear fitting provides good accuracy. Hereinafter, strain data are always given in terms of measured values.

\section{Experimental results and discussions}

\subsection{Effects of curing time}

Fig.5 illustrates the effect of curing time on the ultimate tensile strength and elongation for all specimen groups. It is observed that the small performance increase, both in terms of strength and strain, associated with the control group has little statistical significance. Conversely, the important role played by curing time in reducing the performance decay associated with all aggressive environments is clearly defined. Table 5 gathers the percentage decay against the relevant control group. It shows that moving from 28 to 60 -day curing time reflects on a decay in terms of mechanical properties going from $60 \%$ to $32 \%$ for the AK samples, and from $65 \%$ to $39 \%$ for the SW samples. A similar trend is observed in terms of ultimate strain and the overall pictures resembles what is found in $[18,19]$. Indeed, curing time affects the matrix porosity which has a strong impact on the diffusion of aggressive agents.

\subsection{Optical and SEM analysis}

An optical analysis of 28-day cured specimens is presented in Fig.6 at 35x magnification. While the $\mathrm{CC} 28$ specimen shows a polished reflecting surface, SW28 and especially AK28 specimens are opaque and present diffuse abrasion and salt deposition. Fig.7 is a SEM investigation of the carbon fabric emerging from the failure surface of a AK28 specimen. It suggests that matrix degradation strongly weakens the fabric-to-mortar interface bond, as the carbon yarn surface appears mostly deprived of matrix patches. 


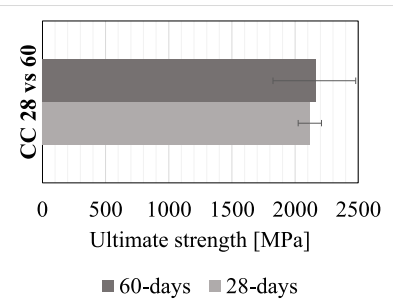

(a)

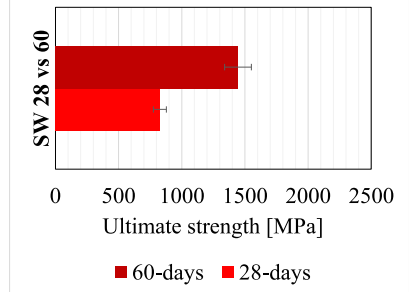

(c)

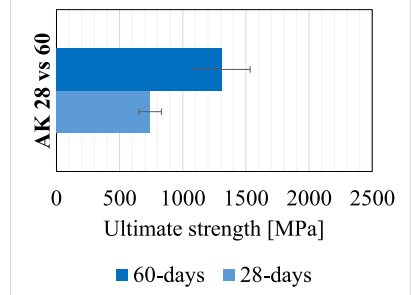

(e)

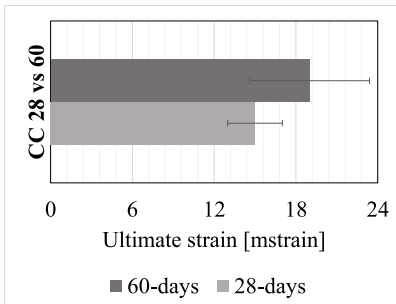

(b)

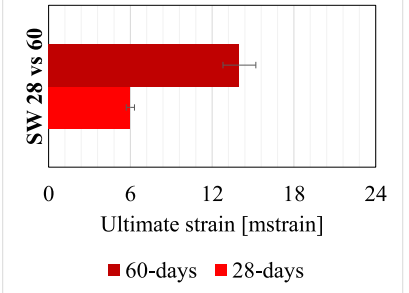

(d)

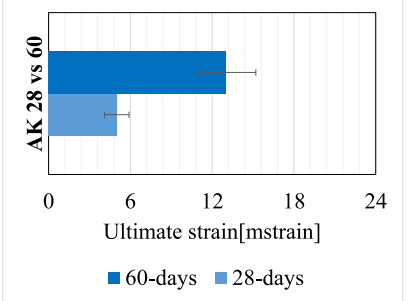

(f)

Figure 5: Bar-chart comparison of mean strength (left) and ultimate strain (right panel) at 28- and 60-day curing-times for all sample groups: (a, b) control (c, d) saline and (e, f) alkaline

\subsection{Crack pattern analysis}

Crack analysis is carried out to relate mechanical properties to the failure mechanism and to matrix deterioration. Indeed, crack spacing provides indirect evidence of interphase bond strength and it affects the apparent composite stiffness [20]. A nice introduction to the significance and application of crack spacing measurement is given in [21, Chap.13]. It is important to observe that crack spacing may be adopted as a design parameter. Besides, crack widening and diffusion clearly affects durability. Fig.8 shows a color map of the longitudinal displacement field for all test group at 28-day curing time ( $\varepsilon=5.5$ mstrain). The control group exhibits several small uniformly colored patches as an evidence of multiple small cracks developing throughout the specimen length. Conversely, the SW and AK groups show few large color patches, which indicate that displacement jumps are concentrated around a small number of wide cracks, with clear negative implications in terms of ductility as well as durability [22].

This qualitative picture is given a quantitative description in Fig.9, that 

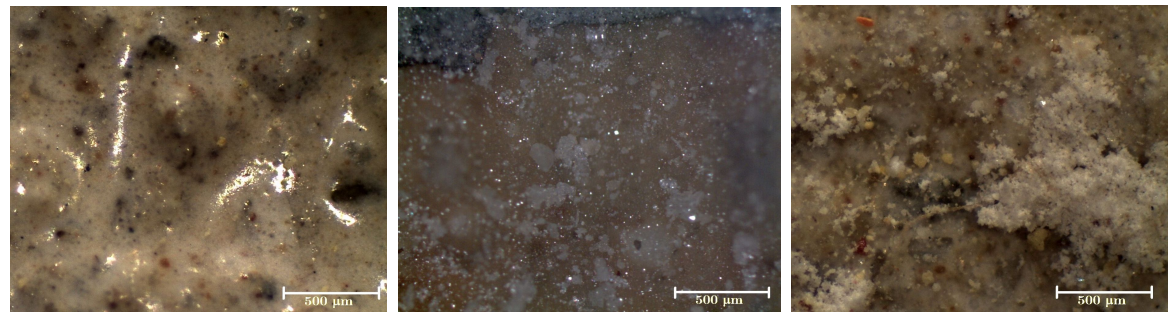

Figure 6: Optical microscopy investigation at 35x magnification of the mortar surface for CC28 (a), SW28 (b) and AK28 (c) specimens

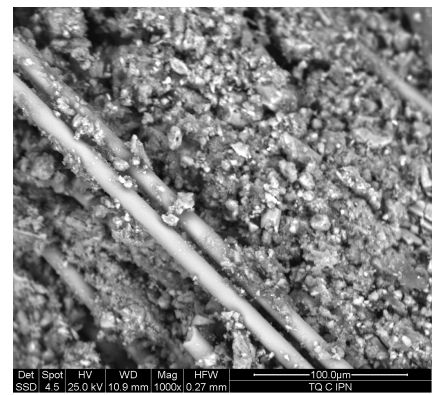

Figure 7: SEM magnification of the carbon fabric emerging from a AK28 failed specimen

plots the average crack spacing as well as the average crack width as a function of strain for AK, SW and CC and it compares 28-day with 60-day curing. In general, crack spacing is a decreasing function of strain, until a saturation level is reached [14]. Conversely, crack width is found to almost linearly increase with strain. Remarkably, the crack pattern development in the control group for 28- and 60-day curing time almost coincide. Conversely, AK and SW specimens display a marked contrast between 28- and 60-day curing, with the crack spacing being almost uniformly twice as large for the former compared to the latter and the crack width increasing at a much slower rate. However, despite this different evolution, the ultimate mean crack width $w_{c r, u}$ attained at failure appears similar for all test groups, as reported in Table 6. Such saturation crack width is located around the mean value $\mu\left(w_{c r, u}\right)=185 \mu \mathrm{m}$ with narrow stan-

\begin{tabular}{c|c|c|c}
\hline Environment & Curing time [days] & Decay in strength [\%] & Decay in strain [\%] \\
\hline AK & 28 & 65 & 64 \\
& 60 & 39 & 33 \\
\hline SW & 28 & 60 & 64 \\
& 60 & 32 & 28 \\
\hline
\end{tabular}

Table 5: Performance decay of mechanical properties for 28- and 60-day curing times 


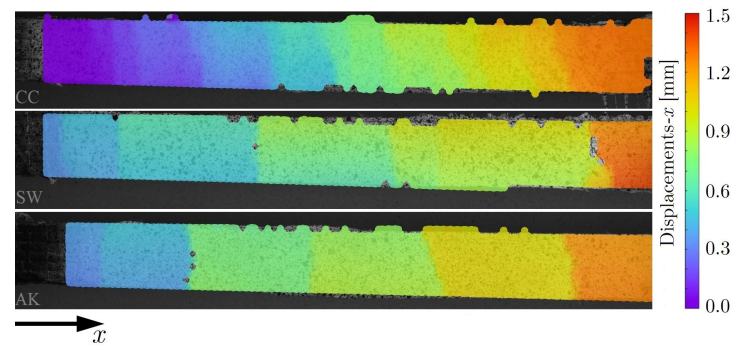

Figure 8: Longitudinal displacement field according to DIC at $\varepsilon=5.5$ mstrain for all specimen groups at 28-day curing time

\begin{tabular}{|c|c|c|c|}
\hline 28-day curing & $\begin{array}{c}w_{c r, u} \\
{[\mu \mathrm{m}]}\end{array}$ & 60-day curing & $\begin{array}{c}w_{c r, u} \\
{[\mu \mathrm{m}]}\end{array}$ \\
\hline CC28 & 193 & CC60 & 161 \\
SW28 & 184 & SW60 & 180 \\
AK28 & 176 & AK60 & 217 \\
\hline
\end{tabular}

Table 6: Average crack width at failure for CC, SW and AK groups

dard deviation $\sigma\left(w_{c r, u}\right)=18 \mu \mathrm{m}$, that corresponds to a unexpectedly limited coefficient of variation, $C V \approx 10 \%$. Thus, it appears that the saturation crack width is a characteristic parameter of this composite system $[23,6]$.

\section{Conclusions}

The effect of aggressive environment exposure on the mechanical performance of carbon fabric mortar composites is investigated, conforming to the recently proposed guidelines [4], through uni-axial traction tests. Carbon fabric is impregnated by a bi-component partly organic liquid agent. Strength curves, ultimate strength and elongation limits as well as crack pattern analysis are presented. The following points summarize the main findings:

- Environmental conditions heavily affect the expected performance and should be carefully taken into account for the computation of the design ultimate values [3]. The alkaline (typical of rural and industrial areas) and saline (seaside, waterfront areas, ports) environments are equally detrimental and produce a strength reduction exceeding $60 \%$ of the control group at 28-day curing. Their action mainly targets the matrix and its bond formation capability.

- Long-term curing provides strong protection against aggressive attack and it should be carefully considered for laminates exposed to adverse environments. Indeed, a remarkable mitigation of performance degradation is observed at 60 -day curing with the performance loss sitting below $40 \%$ of 


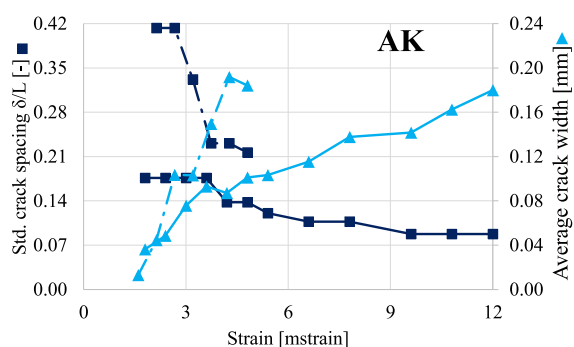

(a)

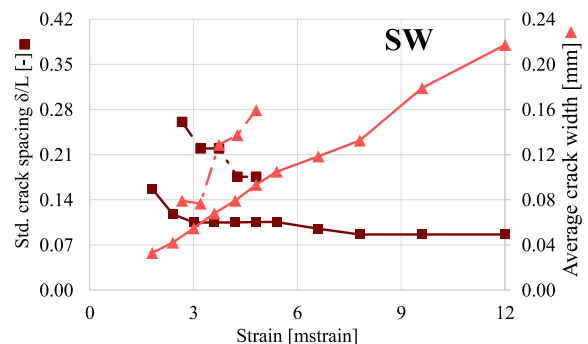

(b)

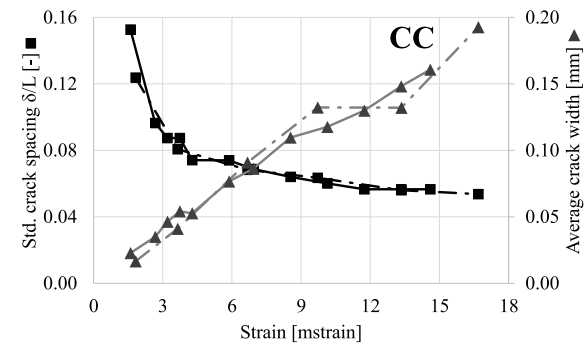

(c)

Figure 9: Crack pattern development during uni-axial traction for $\mathrm{AK}(\mathrm{a}), \mathrm{SW}$ (b) and CC (c) at 28-day (line-dot) and 60-day (solid) curing time. Crack spacing (left scale, triangles) and crack width (right scale, squares) is plotted vs strain

the control group for strength and strain. In contrast, long-term curing provides little benefit in the absence of aggressive attack.

- The crack pattern is a good indication of the degradation occurred in a composite. Interestingly, the limiting value at failure for the crack width seems to define the ultimate strength of the specimen and it appears characteristic of the composite as it is little sensitive to the aggressive environment and to the curing time (saturation crack width).

- The crack pattern evolution strongly depends on the aggressive environment and on the curing time. In contrast, for the control group it is almost entirely independent on the curing time.

\section{Declarations of interest}

None.

\section{Acknowledgments}

Authors gratefully acknowledge financial support from Fondo di Ateneo per la Ricerca FAR2016. 


\section{Bibliography}

[1] Lanzoni L, Nobili A, Tarantino AM. Performance evaluation of a polypropylene-based draw-wired fibre for concrete structures. Construction and Building Materials. 2012;28(1):798-806.

[2] Italian National Research Council (CNR) . Guide for the design and construction of an externally bonded FRP system for strengthening existing structures. DT200. 2004;.

[3] Nobili A, Signorini C. On the effect of curing time and environmental exposure on impregnated Carbon Fabric Reinforced Cementitious Matrix (CFRCM) composite with design considerations. Composites Part B: Engineering. 2017;112:300-313.

[4] ICC-Evaluation Service . Acceptance criteria for masonry and concrete strengthening using fiber-reinforced cementitious matrix (FRCM) composite systems. AC434. 2013; Whittier, CA.

[5] Technical Committee 232-TDT . Test methods and design of textile reinforced concrete. Materials and Structures. 2016;49(12):4923-4927.

[6] Signorini C, Nobili A, Gonzalez EI Cedillo, Siligardi C. Silica coating for interphase bond enhancement of carbon and AR-glass Textile Reinforced Mortar (TRM). Composites Part B: Engineering. 2018;.

[7] Arboleda D. Fabric Reinforced Cementitious Matrix (FRCM) Composites for Infrastructure Strengthening and Rehabilitation: Characterization Methods. PhD thesisUniversity of Miami2014. Open Access Dissertation. Paper 1282.

[8] Arboleda D, Babaeidarabad S, Hays CDL, Nanni A. Durability of Fabric Reinforced Cementitious Matrix (FRCM) Composites. In: CICE 2014; 2014. Vancouver, 20-22 August 2014.

[9] Nobili A. Durability assessment of impregnated Glass Fabric Reinforced Cementitious Matrix (GFRCM) composites in the alkaline and saline environments. Construction and Building Materials. 2016;105:465-471.

[10] Micelli F, Aiello MA. Residual tensile strength of dry and impregnated reinforcement fibres after exposure to alkaline environments. Composites Part B: Engineering. 2017;. available online.

[11] Butler M, Mechtcherine V, Hempel S. Experimental investigations on the durability of fibre-matrix interfaces in textile-reinforced concrete. Cement and Concrete Composites. 2009;31(4):221-231.

[12] Butler M, Mechtcherine V, Hempel S. Durability of textile reinforced concrete made with AR glass fibre: effect of the matrix composition. Materials and structures. 2010;43(10):1351-1368. 
[13] Hempel R, Butler M, Hempel S, Schorn H. Durability of textile reinforced concrete. Special Publication. 2007;244:87-108.

[14] Mobasher B, Peled A, Pahilajani J. Distributed cracking and stiffness degradation in fabric-cement composites. Materials and structures. 2006;39(3):317-331.

[15] Gebler SH, Jones CL, Brogna D, et al. Guide to curing concrete. In: ; 2001.

[16] American Concrete Institute . Recommended practice for curing concrete (ACI 308m). ACI standardAmerican Concrete Institute; 1998.

[17] Nobili A, Lanzoni L, Tarantino AM. Experimental investigation and monitoring of a polypropylene-based fiber reinforced concrete road pavement. Construction and Building Materials. 2013;47:888-895.

[18] Gowripalan N. Effect of curing on durability. Concrete International. 1990;12(2):47-54.

[19] Zhutovsky S, Kovler K. Effect of internal curing on durability-related properties of high performance concrete. Cement and concrete research. 2012;42(1):20-26.

[20] Falope FO, Lanzoni L, Tarantino AM. Modified hinged beam test on steel fabric reinforced cementitious matrix (SFRCM). Composites Part B: Engineering. 2018; In press.

[21] Mobasher B. Mechanics of fiber and textile reinforced cement composites. CRC press; 2011.

[22] Lepech Michael, Li Victor C. Water permeability of cracked cementitious composites. 2005;

[23] Nobili A, Falope FO. Impregnated Carbon Fabric-Reinforced Cementitious Matrix Composite for Rehabilitation of the Finale Emilia Hospital Roofs: Case Study. Journal of composites for construction. 2017;:05017001. 